\title{
Effect of salinity on growth performance and resistance of the clam Cyclina sinensis against Vibrio parahaemolyticus infection
}

\author{
Qian Ni ${ }^{1}$, Wenqian Li ${ }^{1}$, Xuewen Jia ${ }^{1}$, Zhiguo Dong ${ }^{1,2,3}$, \\ Hongxing Ge 1,2,3*
}

\author{
1 Jiangsu Key Laboratory of Marine Bioresources and Environment, Jiangsu Ocean \\ University, Lianyungang, Jiangsu Province 222005, China \\ 2 Jiangsu Key Laboratory of Marine Biotechnolog, Jiangsu Ocean University, Lianyungang, \\ Jiangsu Province 222005, China \\ ${ }^{3}$ Co-Innovation Center of Jiangsu Marine Bio-industry Technology, Jiangsu Ocean \\ University, Lianyungang, Jiangsu Province 222005, China
}

Key words: salinity, stress, clam, growth performance, disease resistance, Vibrio

\begin{abstract}
We examined the growth performance, immune parameters and the susceptibility to Vibrio parahaemolyticus in the clam Cyclina sinensis, which had been reared at different salinity levels of $10 \%$, $20 \%$ and $30 \%$ or 60 days. At the end of the feeding experiment, the biggest shell length and body weight was found in $20 \%$, followed by $30 \%$ and $10 \%$. No significant differences in superoxide dismutase (SOD) activity were observed among the clams held in $10 \%, 20 \%$ and $30 \%$. $\mathrm{Na}^{+} / \mathrm{K}^{+}$-ATPase (NKA) activity of the clams held in $20 \%$ and $30 \%$ o were significantly lower than that in group $10 \%$. The lowest activities of lysozyme (LZM) and glutamic-pyruvic transaminase (GPT) were found in group $10 \%$. The Integrated Biomarker Response index (IBR) values of the clams had an inverse relationship with salinity: $11.28,3.40$ and 2.85 in $10 \%$, $20 \%$ and $30 \%$, respectively. At the end of the feeding experiment, the clams were infected with $V$. parahaemolyticus. As time after infection goes on, the survival rate of clams reared in $20 \%$ was not significantly different with the other two treatments from 24 to $48 \mathrm{~h}$ after infection. However, from 72 to $120 \mathrm{~h}$ after infection, it was significantly lower than those reared in $10 \%$, while it was significantly higher than those reared in $30 \%$ o. It is concluded that the clam C. sinensis reared in $10 \%$ o seawater may reduce growth performance and immune ability, whereas increase resistance against $V$. parahaemolyticus infection.
\end{abstract}




\section{Introduction}

In recent years, the demand for aquatic products including oysters, clams, and fish is constantly growing. The clam Cyclina sinensis (genus Cyclina, family Veneridae) is one of the most important economic clams which is abundant and widely distributed in the coast areas of China, South Korea and Japan and the clam has a lot advantages as a popular consumed seafood, including higher disease resistance, high survival rate and temperature resistance (Ren et al., 2016). In recent years, researchers focused on genetic diversity, disease resistance, and environmental stresses (Lin et al., 2013). Although C. sinensis mostly live in seawater, they exhibit a wide tolerance to salinity (5-35\%o, with an optimum of $15-25 \%$ o) (Lin et al., 2013), especially during the rainy season or after flooding, when they are not able to move quickly enough toward the sea, while exposed to inland low salinity water.

Salinity is one of the most important environmental factors and salinity changes may affect the growth performance and physiology of aquatic organisms. Although lots species of marine animals inhabit wide ranges of salinity, salinity stress is likely to affect aquatic organisms when they are not within their optimal salinity range. For example, it was reported that the pacific white shrimp, Litopenaeus vannamei can inhabit wide ranges of salinity from $1 \%$ o to $40 \%$. And they have a better growth rate at ranges of $15 \%$ o $-20 \%$. Therefore, some of the seasoned shrimp farmers usually add some fresh water to decrease the salinity of the cultivation water to these levels (Pan et al., 2008; Maicá et al., 2017). However, changes in ambient salinity may be a stressor, which influences aquatic animal metabolism, appetite, immune defence and growth performance (Nordlie et al., 2009). Data available shows that salinity did not affect some euryhaline fish species growth, while other species have their growth enhanced in low or high salinities. Therefore, the link between the growth performance and immune defence of aquatic animals and environment salinity has received considerable attention and several studies in recent years have been conducted regarding the influence of different salinities on growth performance and nonspecific immunity of marine animals (Shekhar et al., 2013). The relationships between salinity and growth performance and immune defence of organism have been widely studied in crustaceans (Sang et al., 2014), marine fish (Sidhu et al., 2018), however, they are poorly understood in case of clams. Vibrio parahaemolyticus is the pathogenic Vibrio which has been shown to cause serious infection in mollusk and crustaceans (Raszl et al., 2016; Liang et al., 2017). Whereas there have been very limited studies that have explored the growth and resistance of the clam against $V$. parahaemolyticus infection in response to long-term salinity stress. The present study aimed to better understand the effects of long-term salinity stress on growth performance in the clam $C$. sinensis, and its effects on physiology of the clam $C$. sinensis.

The Clam source, nursery and feeds

\section{Materials and Methods}

Healthy juvenile clams were obtained from a clam hatchery in Weifang City, Shandong Province and the water salinity for seed rearing was $20 \%$. The average shell length and body weight of the clams were $0.46 \pm 0.01 \mathrm{~mm}$ and $0.06 \pm 0.005 \mathrm{~g}$, respectively. Clams were reared in concrete pond $(0.8 \times 0.8 \times 0.4 \mathrm{~m})$ and sterilized muddy sand were sanded on bottom of the pond and the thickness of the mud sand was $5 \mathrm{~cm}$ and the depth of water was $0.2 \mathrm{~m}$. The water had been disinfected with chlorine. Clams were kept at a salinity of $20 \%$, water temperature of $25 \pm 1^{\circ} \mathrm{C}, \mathrm{pH}$ of $7.8 \pm 0.23$. And water was aerated to maintain the dissolved oxygen (DO) level above $5.0 \mathrm{mg} / \mathrm{L}$. The salinity, $\mathrm{pH}$, water temperature and DO were monitored daily using an YSI Model Handheld Instrument (YSI Incorporated, Yellow Springs, Ohio, USA). Clams were fed a mixture of Chlorella vulgaris and Chlorella pyrenoidosa daily. Partial rearing water (1/3) was changed daily.

\section{Experimental design}

The experiment was conducted in concrete pond $(0.8 \mathrm{~m} \times 0.8 \mathrm{~m} \times 0.4 \mathrm{~m})$ and sterilised muddy sand were sanded on bottom of the pond and the thickness of the mud sand was $5 \mathrm{~cm}$ and 
the depth of water was $0.2 \mathrm{~m}$. The water had been disinfected with chlorine. As the clams can survival in the salt concentration between 5\%o-35\%o (Lin, 2012), so approximately two weeks later, clams $(0.64 \pm 0.013 \mathrm{~mm}$ shell length, $0.08 \pm 0.008 \mathrm{~g}$ body weight) were then separated randomly into three groups: a low salinity treatment (10\%o), a medium treatment $(20 \%$ o) and a high salinity treatment (30\%o). Salinity in each treatment was adjusted with fresh water or seawater by about $2 \%$ daily until the salinity in each treatment had reached the desired level. Each group contained three replicates (50 clams/ replicate).

During the experiment, water temperature ranged $24-26^{\circ} \mathrm{C}, \mathrm{pH}$ fluctuated $7.5-8.1, \mathrm{DO}$ concentration ranged $5.1-5.5 \mathrm{mg} / \mathrm{L}$. Clams were fed a mixture of Chlorella vulgaris and Chlorella pyrenoidosa at densities of $5 \times 10^{4}$ and $1 \times 10^{4} \mathrm{cells} / \mathrm{ml}$, respectively. To maintain water quality, partial rearing water (1/3) was changed daily. During the two-month test, we counted the surviving clams as well as and 20 clams from each pond were collected randomly to measure the body weight and shell length every 15 days. After the rearing test, 45 clams in total (three ponds with five clams in each group) were selected randomly for enzyme activities analysis. The gill tissues were separated from the bodies of the clams, washed with precooled Phosphate Buffer solution (PBS) and then preserved at $-80^{\circ} \mathrm{C}$ refrigerator, respectively.

\section{Enzyme activity}

The gill tissues were diluted with PBS at a ratio of 1:9 for the gill tissues weight $(\mathrm{g})$ relative to PBS $(\mathrm{mL})$. The diluted gill tissues homogenate was then used to determine the enzyme activity, including LZM, SOD, NKA and GPT. The total protein contents and the activity of LZM, SOD, NKA and GPT in the diluted tissue sample were measured with an Assay kit respectively (Nanjing Jiancheng Bioengineering Engineering Institute, China), and referring to the kit instruction, the total protein contents and the activity of LZM, SOD, NKA and ACP in the diluted tissue sample were measured (Ge et al., 2019a).

\section{Integrated biomarker response index (IBR)}

IBR is used to integrate all the measured biomarker responses into one general stress index can directly indicate the size of the exposed under the condition of multiple biomarkers of comprehensive response (Beliaeff et al., 2002), and according to Pytharopoulou et al. (Pytharopoulou et al., 2008) the four gill enzyme activities (LZM, SOD, NKA and GPT) were used as biomarkers to calculate the IBR values, where the IBR data was expressed as the area of the triangle formed by two adjacent biomarkers radiation in the star chart. In the star chart with the four enzyme activities represent the direction axes, respectively.

\section{Data processing:}

a. The mean values $\left(X_{i}\right)$ and standard deviation $(S)$ of the duplicates of each biomarker measured in each test group were calculated;

b. The total mean values $(X)$ of each biomarker measured in each test group were calculated;

c. Data normalization: $\mathrm{Xi}^{\prime}=\left(\mathrm{X}_{\mathrm{i}}-\mathrm{X}\right) / \mathrm{S}$, and $\mathrm{X}^{\prime}$ is the normalized value;

d. If there is a positive correlation between biomarkers and pollutants, $Z=X_{i}{ }^{\prime}$; If negative correlation, $\mathrm{Z}=-\mathrm{X}_{\mathrm{i}}{ }^{\prime}$;

e. Obtain the minimum value (Min) of standardized data at all test levels for each biomarker and take the absolute value, and the add its absolute value to $Z$, then obtain $A, A_{i}=Z+\mid$ Min I, A $\geq 0$;

f. Draw the star chart: The magnitude of the score $\left(A_{i}\right)$ for each biomarker at a given concentration level is represented by the length of the radial lines in the star chart. The star chart was drawn with the concentration as the radial coordinate with Excel.

g. Calculate the IBR value directly: The score $A_{i}$ for each biomarker (each radius coordinate in the star chart) is multiplied by the score $A_{i+1}$ for the next biomarker and then divided by 2 as a set of data. The sum of $n$ sets of data is IBR, IBR $=\left(A_{1} * A_{2}\right) / 2+\left(A_{2} * A_{3}\right) / 2+\ldots+\left(A_{n}-\right.$ $\left.{ }_{1}+A_{n}\right) / 2, n$ is the number of radii, i.e., the number of biomarkers. 
Vibrio parahaemolyticus challenge tests by immersion

In order to reduce injection injury, immersion challenge tests were adopted. $V$. parahaemolyticus was isolated from diseased clams. It was cultured in $2216 \mathrm{E}$ fluid nutrient medium at $25{ }^{\circ} \mathrm{C}$ for $48 \mathrm{~h}$. The stock cultures were centrifuged at $7200 \times \mathrm{g}$ for $15 \mathrm{~min}$ at 4 ${ }^{\circ} \mathrm{C}$. The pellet was re-suspended in $10 \%, 20 \%$ and $30 \%$ at $5.2 \times 10^{8} \mathrm{CFU} / \mathrm{mL}$ as the stock bacterial suspension for soak infection.

At the end of the feeding experiment, 90 of the remaining clams were randomly selected from each treatment (30 clams/ replicate) and the clams were immersed in the stock bacterial suspension respectively for $12 \mathrm{~h}$. Then the clams were washed with sterilized seawater and then transferred to $10 \%$, $20 \%$ and 30\%o. At 0, 24, 48, 72, 96 and 120h, the survival clams were counted.

\section{Statistical analysis}

Results are shown as means \pm standard deviation, and data were analyzed by SPSS 19.0 statistical software. Data met the assumptions of normality and homogeneity of variance was assessed with the Shapiro-Wilk test for normality and Levene's test for homogeneity of variance. Then data were analyzed with one-way ANOVA. Differences between experimental groups were determined by a Tukey test with a significance level of $5 \%$.

\section{Results}

Effect of salinity on growth performance of the clam.

During the experiment, the shell length continued to grow (Figure 1). There were no significant differences in shell length of the clam among the treatments on the first day and $15^{\text {th }}$ day. However, the differentiation of shell length emerged from the $30^{\text {th }}$ day to the end, and the biggest shell length was found in $20 \%$, followed by $30 \%$ and $10 \%$, and there were significant differences in shell length between each other $(P<0.05)$.

As shown in Figure 2, on the $30^{\text {th }}$ day and $45^{\text {th }}$ day, there were no significant differences in body weight among $20 \%$ and $30 \%$ o $(P>0.05)$, however, they were significantly higher than that in $10 \%$ o $(P<0.05)$. On the $60^{\text {th }}$ day, the biggest body weight was found in $20 \%$, followed by $30 \%$ and $10 \%$ o $(P<0.05)$.

Effect of salinity on gill enzyme activities of the clam.

As shown in Table 1, Significant differences in LZM activity were observed between the group $10 \%$ and $30 \%$ o $(P<0.05)$, however, there were no significant differences in LZM activity were observed between the group $10 \%$ and $20 \%$ o $(P>0.05)$ and there was also no difference between the group $20 \%$ and $30 \%$ o $(P>0.05)$.

No significant differences in SOD activity were observed among the clams held in $10 \%$, $20 \%$ and $30 \%$ o $(P>0.05)$, and the mean SOD activities varied from $45.67 \pm 1.53$ to $50.33 \pm 3.22 \mathrm{U} / \mathrm{mg}$ prot.

No significant differences in NKA activity were observed among the clams held in $20 \%$ and 30\%o $(P>0.05)$, however, they were significantly lower than that in group 10\%o $(P<0.05)$. Significant differences were observed in GPT activity was observed among the clams held in $10 \%$, $20 \%$ and $30 \%$ o $(P<0.05)$. The lowest GPT activity was found in group $10 \%$, and the highest GPT activity was found in group $20 \%$.

Effect of salinity on IBR of the clams reared in different salinities.

The IBR values were calculated using the gill enzyme activities (LZM, NKA, SOD and GPT)

(Figure 3). The IBR values of the clams had a tendency to increase with salinity decreased and they were $11.28,3.40$ and 2.85 in $10 \%$, 20\%o and 30\%o, respectively (Table 2).

The biomarker star chart for IBR of the clams reared in different salinities (LZM, NKA, SOD and GPT in gills) as is shown in Fig. 3 and the IBR value of the clams under the salinity stress was the area formed by each radius coordinate. In group $10 \%$, GPT made the biggest contributor to IBR, followed by LZM, NKA and SOD. In group 20\%o, LZM made the minimum contributor, followed by SOD and the contributions of GPT and NKA were similar. 
In group $20 \%$, GPT made the minimum contributor, and the other three indicators were similar.

Survival rate (\%) of the clams under V. parahaemlyticus exposure.

As time after infection goes on, the survival rates showed a decreasing trend along with the increase in salinity (Figure 4). For the clams held in $30 \%$, mass mortality was observed in $48 \mathrm{~h}$, and the survival rates were significantly lower than those held in $10 \%$ o and $20 \%$ o $(P<0.05)$ from 24 to $120 \mathrm{~h}$. For the clams held in $20 \%$, the survival rate had not significant difference with the other two treatments from 24 to $48 \mathrm{~h}$. However, it was significantly lower than those reared in $10 \%$ o $(P<0.05)$, whereas it was significantly higher than those reared in $30 \%$ o $(P<0.05)$.

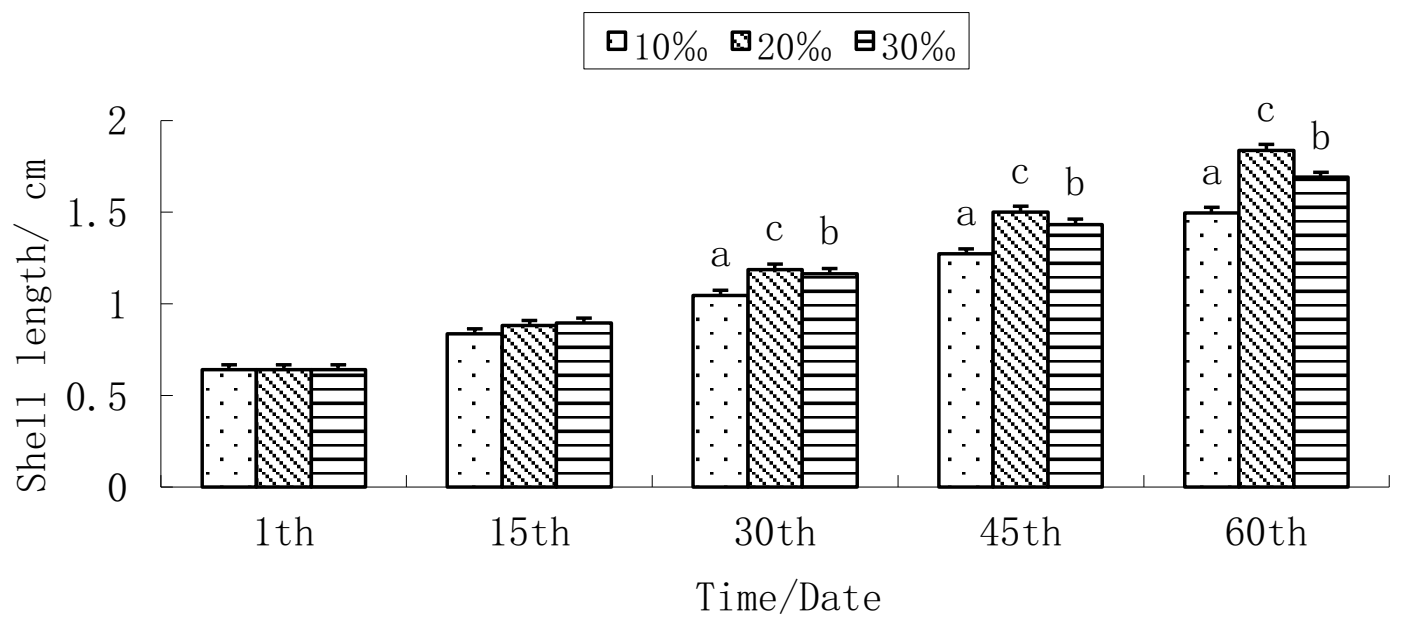

Figure 1 Shell length of the Venus clam reared in different salinities. Values are indicated as mean \pm SEM and $\mathrm{N}=60$ individuals. Statistical significances $(P<0.05)$ are indicated by similar letters $(a, b$, C).

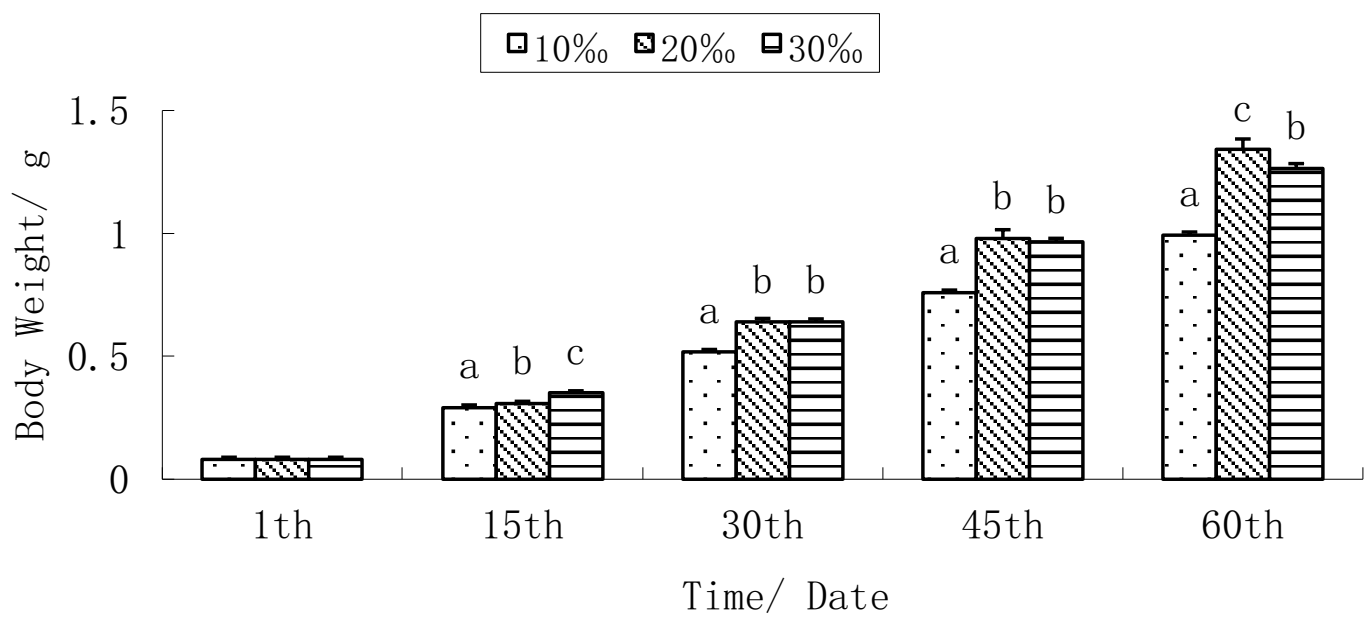

Figure 2 Body weight of the Venus clam reared in different salinities. Values are indicated as mean \pm SEM and $N=60$ individuals. Statistical significances $(P<0.05)$ are indicated by similar letters $(a, b$, C).

Table 1 Gill enzyme activities of Venus clam reared in different salinities

\begin{tabular}{lllll}
\hline Salinity & LZM $(\mathrm{U} / \mathrm{g}$ prot $)$ & SOD $(\mathrm{U} / \mathrm{mg}$ prot $)$ & NKA(U/mg prot $)$ & GPT (U/g prot) \\
\hline $10 \%$ oo & $39.23 \pm 2.70^{\mathrm{a}}$ & $47.67 \pm 2.89^{\mathrm{a}}$ & $1.46 \pm 0.14^{\mathrm{b}}$ & $56.33 \pm 1.53^{\mathrm{a}}$ \\
$20 \% \mathrm{o}$ & $44.00 \pm 3.61^{\mathrm{ab}}$ & $50.33 \pm 3.22^{\mathrm{a}}$ & $1.20 \pm 0.05^{\mathrm{a}}$ & $86.67 \pm 4.12^{\mathrm{c}}$ \\
$30 \% \mathrm{o}$ & $47.33 \pm 3.06^{\mathrm{b}}$ & $45.67 \pm 1.53^{\mathrm{a}}$ & $1.22 \pm 0.06^{\mathrm{a}}$ & $70.20 \pm 2.99^{\mathrm{b}}$ \\
\hline
\end{tabular}


Note: Within the same columns, Values are indicated as mean \pm SEM and $N=15$ individuals. Statistical significances $(P<0.05)$ are indicated by similar letters $(a, b)$.

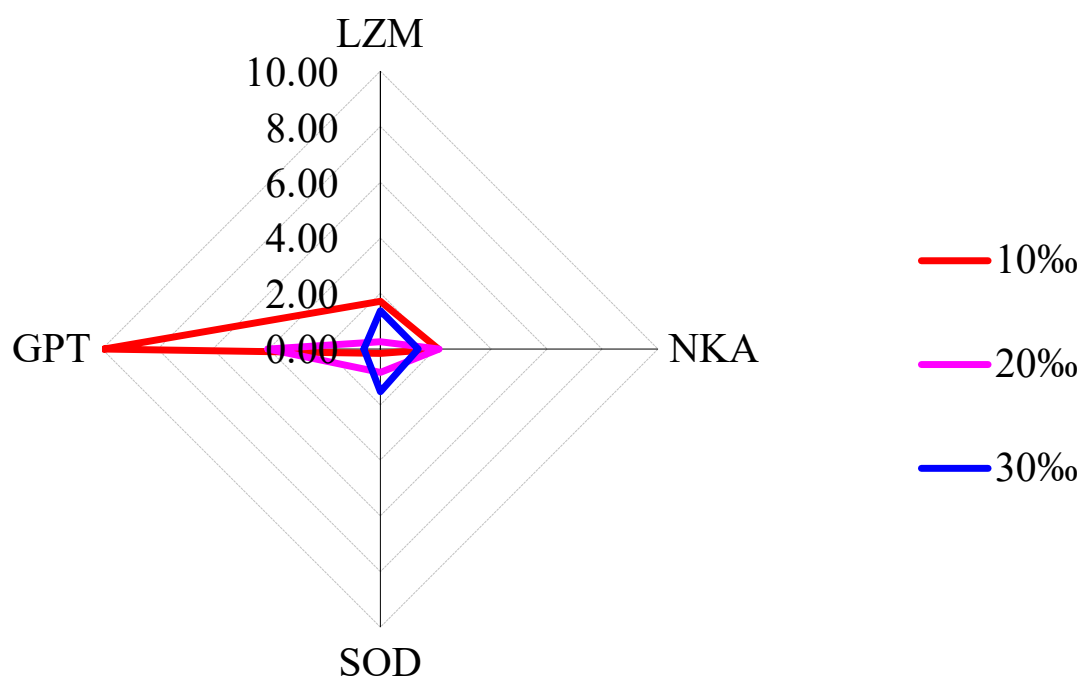

Figure 3 The biomarker star chart for IBR of the Venus clam reared in different salinities (LZM, NKA, SOD and GPT in gills). Values are indicated as mean \pm SEM and $\mathrm{N}=15$ individuals. Statistical significances $(P<0.05)$ are indicated by similar letters $(a, b, c)$.

Table 2 IBR of the Venus clam reared in different salinities (LZM, NKA, SOD and GPT in gells)

\begin{tabular}{llll}
\hline Salinity & $10 \%$ o & $20 \%$ o & $30 \%$ o \\
\hline IBR & 11.28 & 3.40 & 2.85 \\
\hline
\end{tabular}

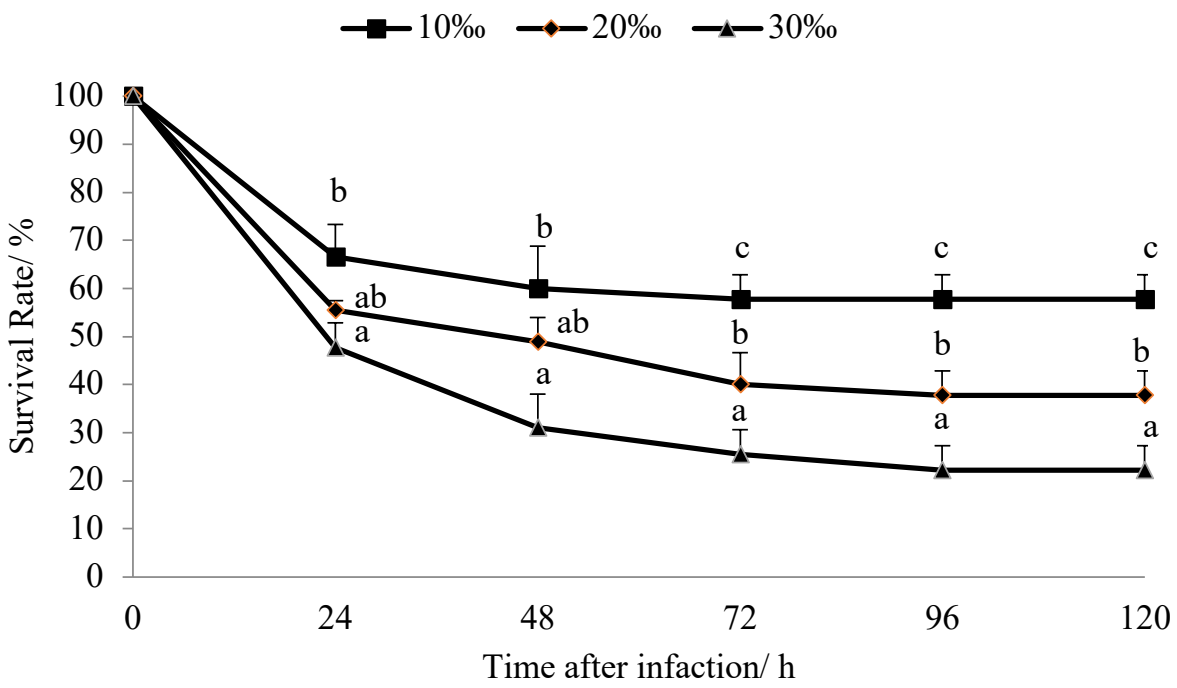

Figure 4 Survival rate of the clams reared in different salinities after V. parahaemolyticus challenge. Values are indicated as mean \pm SEM and $N=90$ individuals. Statistical significances $(P<0.05)$ are indicated by similar letters $(\mathrm{a}, \mathrm{b}, \mathrm{c})$.

\section{Discussion}

Salinity stress affects aquatic animal when it is not in its optimal salinity range (Árnason et al., 2013) and stress conditions decrease its growth performance (Abou Anni et al., 2016). In the present study, the biggest shell length was found in $20 \%$, followed by $30 \%$ o and $10 \%$ on $6.30,7.15$ and 7.30 . As for the slow growth of the clams in group $30 \%$ and 
$10 \%$, this might result from that uncomfortable salinity decreased the oxygen consumption, feeding rate and filtration of the clams. This indicated that $10 \%$ and $30 \%$ o were probably not the optimal salinity of the clams (Mattioli et al., 2017). Stress conditions increase energy demand required for aquatic animals (Devreker et al., 2009). In fact, the isosmotic point for lots of marine animals such as $L$. vannamei and the clam Pinctada margaritifera are repotted to nearly be $20 \%$ (Andrew et al., 2017) and $24 \%$ (Shakhmatova et al., 2006). Salinities approaching the isosmotic point, marine animals don't have to expend lots of energy hypoosmoregulating or hyperosmoregulating to maintain their haemolymph osmolality. For example, $L$. vannamei have to hyperosmoregulate at the lower salinities and they have the best growth performance at approximately $20 \%$ (Maicá et al., 2017). Other sea animals such as Atlantic cod (Gadus morhua) (Árnason et al., 2013), pompano Trachinotus marginatus (Anni, 2016) and other sea animals have the similar phenomena. This has the advantage of lower energetic costs of osmoregulation, lower standard metabolic rate and a larger proportion of ingested energy being directed towards growth (Barman et al., 2005). The optimum salinity for the clams is $15-25 \%$ (Lin et al., 2013), and the biggest body weight was found in $20 \%$, followed by $30 \%$ and $10 \%$ at the end of the feeding trial. Therefore, salinities approaching the isosmotic point can improve aquatic organisms' growth, and this agrees with the result of the present study.

LZM is one of the most impotent nonspecific immunities of the mollusk and it is a commonly used biomarker in immunotoxicity studies (Shekhar et al., 2013). Previous studies have demonstrated that too low salinity could decrease LZM activity and it is generally recognized that reduced LZM activities may result in decreased resistance to bacterial challenge (Hart et al., 2016). In the present study, we found that the LZM activities were reduced along with the salinity decreased. This fact indicated that LZM activity may reduce for the clams reared in low salinity water.

SOD is responsible for scavenging superoxide radicals and SOD can be affected by the aquatic environmental factors such as dissolved oxygen, salinity and $\mathrm{pH}$ in aquatic animals (Zheng et al., 2017). In the present study, the clams when transferred to $10 \%$ o decreased SOD activity, as compared to which reared in $20 \%$. However, it was higher than which reared in $30 \%$. This fact indicated that a decrease in the activity of SOD may be responsible for the release of superoxide anion when the clams reared in low salinity water. This is consistent with that $L$. vannamei when transferred to $5 \%$ and $15 \%$ o decreased SOD activity, as compared to the white shrimp reared in $25 \%$ and $30 \%$ (Maicá et al., 2017). In the present study, no significant differences in SOD activity were observed among the clams held in $10 \%, 20 \%$ and $30 \%$. The results indicated that the clams might be with a higher tolerance capacity to salinity change (20\%o to $10 \%$ or $20 \%$ o to $30 \%$ o). This is probably because that the clam faced salinity associated stresses, they can alter their biochemical mechanisms such as increasing their antioxidant defenses to deal with the higher oxidative stress resulting from salinity condition.

Gill NKA activity in aquatic animal plays an essential role in the processes of ion uptake and ion excretion which are advantageous to regulation of cell osmotic pressure and promote cell growth normally. Acute change of environmental factors can result in the disorders of the regulation of osmotic pressure. In the present study, NKA activity in the clams reared in $20 \%$ and $30 \%$ was observed significantly lower than that in $10 \%$. According to Laiz-Carrión, any reduction in gill NKA activity might suggest a lower energy cost for osmotic regulation and save energy for other metabolism, such as body growth (Laiz-Carrión et al., 2005). This fact indicated that compared to $10 \%$, the salinity fluctuation (20\%o - 30\%o) may be the salinity setting range. And this is consisted with the present study that the clams reared in $20 \%$ and $30 \%$ had a better grow performance than those in $10 \%$.

GPT is one of essential enzymes in aquatic animals related to the transfer of amino groups from one specific amino acid to another which involved in the synthesis and catabolism of amino acids (Rathnakumaria et al., 2018). Significant differences were observed in GPT activity was observed among the clams held in 10\%o, 20\%o and 30\%o and the lowest GPT activity was found in group 10\%, and the highest GPT activity was 
found in group $20 \%$ in the present study. This fact indicated that salinity changes might have a negative effect on the metabolism of amino acid. Han et al (Han et al., 2014) and Tang et al (Tang et al., 2013) reported that dietary taurine, glutamin and tryptophan can elevate GPT to promote the metabolism of amino acid. This indicated that we can regulate GPT with in the clams reared in low salinity.

IBR complement to and enhance reliability on the toxicology experimental data, offer more visualized and biologically relevant information on the potential impact of environmental pollutants on the health of aquatic animals (Barda et al., 2014). Therefore, we can obtain an integrated and visualized evaluation of the effects of environmental stress factors in mollosc. IBR has been used to assess toxically-induced stress level of pollution or describe the stress period of the pollution generally (Fossi et al., 2013). In addition, a lot recent reports showed that the measurement of enzymatic activity biomarkers can be a good illustration of stress exposure (Ge et al., 2019b). In the present study, the lowest values of IBR were calculated in $30 \%$, suggesting the minimum impact of this salinity on the clams. The highest values of IBR were found in $10 \%$, indicating that the maximum effect of the salinity on the clams. This is consistent with that $5 \%$ o- $35 \%$ was the adaptable salinity with the optimum of 15\%o-25\%o for the clams (Lin, 2013).

$V$. parahaemolyticus has been recognized as one of the pathogens and it can lead to massive mortalities in clams (Kang et al., 2017). In the present study, mass mortality of the clams reared in different salinities after $V$. parahaemolyticus infection was recorded in $72 \mathrm{~h}$. This is probably because the vibrio multiplied in the body which may have a lot to do with the deaths. It is known that environment parameters such as temperature and salinity affect the growth of pathogens and their production of toxins (Pan et al., 2008). V. parahaemolyticus can grow well in seawater containing $\mathrm{NaCl}$ from $5 \%$ o to $45 \%$ o with optimum at $25 \%$ o to $35 \%$. For example, $V$. parahaemolyticus incubated in TSB containing $25 \%$ o NaCl displayed more virulence in Penaeus monodon (Sarter et al., 2011). In the present study, as time after infection goes on, survival rates showed a decreasing trend along with the increase in the salinity. This is probably because that $V$. parahaemolyticus is halophiles that require salt for growth and various studies have reported on the increment in the numbers and toxins of Vibrio as the water salinity increases (Kang et al., 2017; Soto-Rodriguez et al., 2016).

\section{Acknowledgements}

The authors are grateful to all the laboratory members for experimental material preparation and technical assistance. This work was supported by Youth Talent Program Supported by the National key research and development projects (2019YFD0900403), Natural Science Foundation of the Jiangsu Higher Education Institutions of China (18KJA240001), China Agriculture Research System (CARS-49), the Priority Academic Program Development of Jiangsu, the Project of Jiangsu Fisheries Science and Technology (Y2018-27), the Project of Jiangsu Key Laboratory of Marine Biotechnology (No. HS2017002) and the Huaihai Institute of Technology start-up funds (No. KQ17022).

\section{References}

Abou Anni, I., Bianchini, A., Varela, A., 2016. Salinity influence on growth, osmoregulation and energy turnover in juvenile pompano Trachinotus marginatus Cuvier 1832. Aquaculture, 455: 63-72. https://doi.org/ 10.1016/j.aquaculture.2016.01.010

Andrew, J., Jeffrey, M., 2017. Comparing salinities of 10, 20, and $30 \%$ in intensive, commercial-scale biofloc shrimp (Litopenaeus vannamei) production systems. Aquaculture, 476: 29-36. https://doi.org/10.1016/j.aquaculture.2017.03.047

Anni, I., Bianchini, A., Barcarolli, I., Junior, A., 2016. Salinity influence on growth, osmoregulation and energy turnover in juvenile pompano Trachinotus marginatus Cuvier 1832. Aquaculture, 455:63-72. https://doi.org/10.1016/j.aquaculture.2016.01.010

Árnason, T., Magnadóttir, B., Björnsson, B., 2013. Effects of salinity and temperature on growth, plasma ions, cortisol and immune parameters of juvenile Atlantic cod (Gadus morhua). Aquaculture, 380-383: 70-79. https://doi.org/10.1016/j.aquaculture.2012.11.036 
Barda, I., Purina, I., Rimsa, E., 2014. Seasonal dynamics of biomarkers in infaunal clam Macoma balthica from the Gulf of Riga (Baltic Sea). J. Marine Syst, 129: 150-156. https://doi.org/10.1016/j.jmarsys.2013.05.006

Barman, U.K., Jana, S.N., Garg, S.K., 2005. Effect of inland water salinity on growth, feed conversion efficiency and intestinal enzyme activity in growing grey mullet, Mugil cephalus (Linn.): field and laboratory studies. Aquac. Int, 13: 241-256. https://doi.org/10.1007/s10499-004-2479-5

Beliaeff, B., Burgeot, T., 2002. Integrated biomarker response: a useful tool for ecological risk assessment. Environ. Toxicol. Chem, 21:1316-1322. https://doi.org/10.1002/etc.5620210629

Devreker, D., Souissi, S., Winkler, G., 2009. Effects of salinity, temperature and individual variability on the reproduction of Eurytemora affinis (Copepoda; Calanoida) from the Seine estuary: a laboratory study. J. Exp. Mar. Biol. Ecol., 368: 113-123. https://doi.org/10.1016/j.jembe.2008.10.015

Fossi, O. T., Buffet, P.E., Amiard, J.C., 2013. Integrated assessment of estuarine sediment quality based on a multi-biomarker approach in the bivalve Scrobicularia plana. Ecotox. Environ. Safe., 88: 117-125. https://doi.org/10.1016/j.ecoenv.2012.11.004

Ge, H.X., Ni, Q., Li, J., 2019a. Integration of white shrimp (Litopenaeus vannamei) and green seaweed (Ulva prolifera) in minimum-water exchange aquaculture system. J. Appl. Phycol. , 31: 1425-1432. https://doi.org/10.1007/s10811-018-1601-4

Ge, H.X., Ni, Q., Li, J., 2019b. Effects of short period feeding polysaccharides from marine macroalga, Ulva prolifera on growth and resistance of Litopenaeus vannamei against Vibrio parahaemolyticus infection. J. Appl. Phycol., 31(3): 2085-2092. https://doi.org/10.1007/s10811-018-1663-3

Han, Y., Koshio, S., Jiang, Z., 2014. Interactive effects of dietary taurine and glutamine on growth performance, blood parameters and oxidative status of Japanese flounder Paralichthys olivaceus. Aquaculture, 348: https://doi.org/10.1016/j.aquaculture.2014.08.036

Hart, C., Lauth, M., Hunter, C., 2016. The Effects of 4-nonylphenol on the Immune Response of the Pacific oyster, Crassostrea gigas, Following Bacterial Infection (Vibrio campbellii). Fish Shellfish Immunol., 58: 449-461. https://doi.org/10.1016/j.fsi.2016.09.054

Kang, C.H., Shin, Y., Jang, S., Yu, H., Kim, S., An, S., Park, K., So, J.S., 2017. Characterization of Vibrio parahaemolyticus isolated from oysters in Korea: Resistance to various antibiotics and prevalence of virulence genes. Mar. Pollut. Bull., 118 (1): 261-266. https://doi.org/10.1016/j.marpolbul.2017.02.070

Laiz-Carrión, R., Sangiao-Alvarellos, S., M.Guzmán, J., Río, M., Soengas, J., Mancera, J., 2005. Growth performance of gilthead sea bream Sparus aurata in different osmotic conditions: Implications for osmoregulation and energy metabolism. Aquaculture, 250: 849-861. https://doi.org/10.1016/j.aquaculture.2005.05.021

Liang, B., Jiang, F., Zhang, S., Yue, X., Wang, H., Liu, B., 2017. Genetic variation in Vibrio resistance in the clam Meretrix petechialis under the challenge of Vibrio parahaemolyticus. Aquaculture, 468, 458-463. https://doi.org/10.1016/j.aquaculture.2016.10.037

Lin, T., Lai, Q., Yao, Z., Lu, J., Zhou, K., Wang, H., 2013. Combined effects of carbonate alkalinity and $\mathrm{pH}$ on survival, growth and haemocyte parameters of clam Cyclina sinensis. Fish Shellfish Immunol., 35(2): 525-531. https://doi.org/10.1016/j.fsi.2013.05.006

Mattioli, C., Takata, R., Leme, F., 2017. The effects of acute and chronic exposure to water salinity on juveniles of the carnivorous freshwater catfish Lophiosilurus alexandri. Aquaculture, 481: 255-266. https://doi.org/10.1016/j.aquaculture.2017.08.016

Maicá, P., de Borba, M., Wasielesky, W., 2017. Effect of low salinity on microbial floc composition and performance of Litopenaeus vannamei (Boone) juveniles reared in a zerowater-exchange super-intensive system. Aquac. Res., 43 (3): 361-370. https://doi.org/10.1111/j.1365-2109.2011.02838.x 
Nordlie, F.G., 2009. Environmental influences on regulation of blood plasma/serum components in teleost fishes: a review. Rev. Fish Biol. Fish., 19: 481-564. https://doi.org/10.1007/s11160-009-9131-4

Pan, L., Hu, F., Jing, F., 2008. The effect of different acclimation temperatures on the prophenoloxidase system and other defence parameters in Litopenaeus vannamei. Fish Shellfish Immunol, 25(1):137-142. https://doi.org/10.1016/j.fsi.2008.03.016

Prymaczok, N., Chaulet, A., Medesani, D., 2012. Survival, growth, and physiological responses of advanced juvenile freshwater crayfish (Cherax quadricarinatus), reared at low temperature and high salinities. Aquaculture, 334-337: 176-181. https://doi.org/10.1016/j.aquaculture.2011.12.032

Pytharopoulou, S., Sazakli, E., Grintzalis, K., 2008. Translational responses of Mytilus galloprovincialis to environmental pollution: integrating the responses to oxidative stress and other biomarker responses into a general stress index. Aquat. Toxicol., 89(1): 18-27. https://doi.org/10.1016/j.aquatox.2008.05.013

Raszl, S.M., Froelich, B.A., Vieira, C.R., Blackwood, D.A., Noble, R.T., 2016. Vibrio parahaemolyticus and Vibrio vulnificus in South America: water, seafood, and human infections. J. Appl. Microbiol., 121 (5), 1201-1222. https://doi.org/10.1111/jam.13246

Rathnakumaria, P., Kolanchinathana, P., Sivab, D., 2018. Antibacterial efficacy of seagrass Cymodocea serrulata-engineered silver nanoparticles against prawn pathogen Vibrio parahaemolyticus and its combative effect on the marine shrimp Penaeus monodon. Aquaculture, 493: 158-164. https://doi.org/10.1016/j.aquaculture.2018.04.061

Ren, Y., Pan, H., Yang, Y. 2016. Molecular cloning, characterization and functional analysis of a heat shock protein 70 gene in Cyclina sinensis. Fish Shellfish Immunol., 58: 663-668. https://doi.org/10.1016/j.fsi.2016.10.009

Sang, H., Fotedar, R., 2004. Growth, survival, haemolymph osmolality and organosomatic indices of the western king prawn (Penaeus latisulcatus Kishinouye, 1896) reared at different salinity. Aquaculture, 234: 601-14. https://doi.org/10.1016/j.aquaculture.2004.01.008

Sarter, S., Randrianarivelo, R., Ruez, P., Raherimandimby, M., Danthu, P., 2011. Antimicrobial effects of essential oils of Cinnamosma fragrans on the bacterial communities in the rearing water of Penaeus monodon larvae. Vector Borne Zoonotic Dis., 11 (4): 433437. https://doi.org/10.1089/vbz.2010.0069

Shakhmatova, E.I., Berger, V.Ya., Natochin, Yu.V., 2006. Cations in molluscan tissues at sharply different hemolymph osmolality. Biol. Bull., 33: 269-275. https://doi.org/10.1134/S1062359006030095.

Shekhar, M., Kiruthika, J., Ponniah, A., 2013. Identification and expression analysis of differentially expressed genes from shrimp (Penaeus monodon) in response to low salinity stress. Fish Shellfish Immunol., 35(6): 1957-1968. https://doi.org/10.1016/j.fsi.2013.09.038

Sidhu, P., Smith, S., Mayer, C., 2018. Comparative pharmacokinetics of oxytetracycline in tilapia (Oreochromis spp.), maintained at three different salinities. Aquaculture, 495 (1): 675-681. https://doi.org/10.1016/j.aquaculture.2018.06.044

Tang, L., Feng, L., Sun, C., 2013. Effect of tryptophan on growth, intestinal enzyme activities and TOR gene expression in juvenile Jian carp (Cyprinus carpio var. Jian): Studies in vivo and in vitro. Aquaculture, 412-413: 23-33. https://doi.org/10.1016/j.aquaculture.2013.07.002

Soto-Rodriguez, S.A., Gomez-Gil, B., Lozano-Olvera, R., Betancourt-Lozano, M., Morales-Covarrubias, M.S., 2015. Field and experimental evidence of Vibrio parahaemolyticus as the causative agent of acute hepatopancreatic necrosis disease of cultured shrimp (Litopenaeus vannamei) in Northwestern Mexico. Appl. Environ. Microbiol. 81 (5), 1689-1699. https://doi.org/10.1128/AEM.03610-14

Zheng, X., Duan, Y., Dong, H., 2017. Effects of dietary Lactobacillus plantarum in different treatments on growth performance and immune gene expression of white shrimp Litopenaeus vannamei under normal condition and stress of acute low Salinity. Fish Shellfish Immunol., 62: 195-201. https://doi.org/10.1016/j.fsi.2017.01.015 
